\title{
Accuracy of three different fecal calprotectin tests in the diagnosis of inflammatory bowel disease
}

\author{
Hui Won Jang ${ }^{1}$, Hyun Sook Kim², Soo Jung Park ${ }^{1}$, Sung Pil Hong ${ }^{1}$, Tae Il Kim , Won Ho Kim \\ Jae Hee Cheon ${ }^{1}$ \\ Departments of Internal Medicine, Institute of Gastroenterology and ${ }^{2}$ Laboratory Medicine, Yonsei University College of Medicine, Seoul, Korea
}

Background/Aims: Several studies have found that the measurement of fecal calprotectin is useful for the early diagnosis of inflammatory bowel disease (IBD). We compared the effectiveness of three different fecal calprotectin kits for initial diagnosis in patients with suspected IBD. Methods: We enrolled 31 patients with IBD (18 Crohn's disease [CD], 11 ulcerative colitis [UC], and two intestinal Behçet's disease), five with irritable bowel syndrome (IBS), and five with other colitis (four infectious colitis and one intestinal tuberculosis). Diagnosis was based on clinical, laboratory, and endoscopic examinations. Fecal samples were obtained at the first diagnosis and calprotectin levels were measured using three different kits (Quantum Blue ${ }^{\circledR}$ Calprotectin, EliA $^{\mathrm{TM}}$ Calprotectin, and RIDASCREEN ${ }^{\circledR}$ Calprotectin). Results: The overall accuracy for differentiating IBD from IBS or other colitis was $94 \%$ and $91 \%$, respectively, for Quantum Blue ${ }^{\circledR}$ (cutoff, $50 \mu \mathrm{g} / \mathrm{g}$ ); $92 \%$ and $89 \%$, respectively, for EliA ${ }^{\mathrm{TM}}$ (cutoff, $50 \mu \mathrm{g} / \mathrm{g}$ ); and $82 \%$ and $76 \%$, respectively, for RIDASCREEN ${ }^{\circledR}$ (cutoff, $50 \mu \mathrm{g} / \mathrm{g}$ ). In patients with CD, the results of Quantum Blue ${ }^{\circledR}$ Calprotectin and Elie ${ }^{\mathrm{TM}}$ Calprotectin correlated significantly with levels of the Crohn's disease activity index (Spearman's rank correlation coefficient, $r=0.66$ and $r=0.49$, respectively). In patients with UC, the results of Eli ${ }^{\mathrm{TM}}$ Calprotectin correlated significantly with the Mayo score ( $\mathrm{r}=0.70)$. Conclusions: Fecal calprotectin measurement is useful for the identification of IBD. The overall accuracies of the three fecal calprotectin kits are comparable. (Intest Res 2016;14:305-313)

Key Words: Fecal calprotectin; Inflammatory bowel disease; Irritable bowel syndrome

\section{INTRODUCTION}

Fecal calprotectin has been proposed as a candidate diagnostic marker for discrimination between IBD and IBS. Calprotectin is a heterodimer of the calcium-binding proteins S100A8 and S100A9 and is present mainly in neutrophils. ${ }^{1}$

Received December 22, 2015. Revised March 15, 2016.

Accepted March 28, 2016.

Correspondence to Jae Hee Cheon, Department of Internal Medicine, Yonsei University College of Medicine, 50-1 Yonsei-ro, Seodaemun-gu, Seoul 03722, Korea. Tel: +82-2-2228-1990, Fax: +82-2-393-6884, E-mail: geniushee@yuhs.ac

Financial support: This study was supported in part by the Korean Health Technology R\&D Project through the Korea Health Industry Development Institute (KHIDI) and funded by the Ministry of Health and Welfare, Republic of Korea (grant numbers: A111428, HI13C1345, and HI12C0130). It was also supported by the Basic Science Research Program through the National Research Foundation of Korea funded by the Ministry of Science, ICT \& Future Planning (NRF-2014R1A1A1008096). Conflict of interest: None.
Neutrophils migrate into the bowel lumen as a result of an inflammatory process, and the level of fecal calprotectin strongly correlates with the degree of intestinal inflammation. ${ }^{2}$ Moreover, calprotectin concentration distinguishes IBD from normal findings or functional disorders such as IBS. ${ }^{3}$ Several studies have shown that the calprotectin level can be used to identify IBD, ${ }^{4-7}$ to assess the response to IBD therapy, ${ }^{7-14}$ and to predict an IBD relapse. ${ }^{7,15-18}$ Furthermore, fecal calprotectin analysis is noninvasive and easily accessible in comparison to colonoscopy with a biopsy, which is the gold standard for assessment of gastrointestinal inflammation. $^{19,20}$

Since identification of fecal calprotectin as a potential biomarker, many types of calprotectin test kits have been developed. ELISAs have been typically used to quantify fecal calprotectin. Recently, quantitative immunochromatographic point-of-care tests or immunoassays were developed as

\footnotetext{
(c) Copyright 2016. Korean Association for the Study of Intestinal Diseases. All rights reserved.

This is an Open Access article distributed under the terms of the Creative Commons Attribution Non-Commercial License (http://creativecommons.org/licenses/by-nc/4.0)

which permits unrestricted non-commercial use, distribution, and reproduction in any medium, provided the original work is properly cited.
} 
a reliable alternative to the more time-consuming ELISA methods. ${ }^{21,22}$ Nonetheless, these calprotectin test kits vary in characteristics, and few data are available regarding clinical comparison. A comparison of different calprotectin test kits may help clinicians in choosing the appropriate assay.

We designed this study to evaluate the initial diagnostic ability of three fecal calprotectin kits-Quantum Blue ${ }^{\circledR}$ Calprotectin, EliA ${ }^{\mathrm{TM}}$ Calprotectin, and RIDASCREEN ${ }^{\circledR}$ Calprotectin-in different bowel diseases. Furthermore, we tested whether the results produced by these fecal calprotectin kits correlate with disease activity and location of CD or UC.

\section{METHODS}

\section{Subjects}

We screened 52 patients who visited Severance Hospital from July to December 2014 for a workup because of abdominal pain, changes in bowel habits, and/or anorectal bleeding. We excluded patients who met any of the following criteria: incomplete colonoscopy, inability to collect fecal samples, colorectal cancer, history of bowel resection, an uncertain diagnosis after colonoscopy, or regular intake of aspirin and/or NSAIDs. Of a total of 52 screened patients, 11 were excluded: two for a lack of fecal samples, one for colorectal cancer, and eight for unclear diagnoses (Fig. 1). Finally, 41 patients were enrolled in this study.

The patients were classified into three groups: IBD (CD, UC, and intestinal Behçet's disease), IBS, and "other colitis." The latter group was defined as patients with a bowel disease other than IBD and IBS and included patients with infectious colitis and intestinal tuberculosis. The diagnosis of a bowel disease was established on the basis of a clinical history, laboratory results, endoscopic findings, pathology, and radiologic analyses according to the diagnostic criteria. We also assessed disease severity using CDAI in patients with
$\mathrm{CD}$ and the Mayo score in patients with UC. CRP was quantified by an immunoturbidimetric method and the cutoff was $8 \mathrm{mg} / \mathrm{L}$. All the enrolled patients underwent complete colonoscopy. The data were collected in a prospective manner and analyzed retrospectively.

The study protocol adheres to the 1975 Declaration of Helsinki guidelines and was approved by the Institutional Review Board of Yonsei University College of Medicine (approval number: 4-2015-1117). Each participant or legal guardian provided written informed consent for diagnosis and treatment.

\section{Fecal Calprotectin}

Fecal samples were obtained at the first diagnosis and fecal calprotectin levels were measured with three kits: Quantum Blue ${ }^{\circledR}$ Calprotectin, EliA ${ }^{\mathrm{TM}}$ Calprotectin, and RIDASCREEN $^{\circledR}$ Calprotectin. The laboratory technician conducting the tests was blinded to the patient's clinical information. All the tests were performed according to the manufacturers' instructions.

The Quantum Blue ${ }^{\circledR}$ Calprotectin kit (Bühlmann Laboratories, Basel, Switzerland) was provided by WOONGBEE MeDiTech (Seongnam, Korea). Fecal samples were diluted 1:50, and the cutoff was $50 \mu \mathrm{g} / \mathrm{g}$. EliA ${ }^{\mathrm{TM}}$ Calprotectin (Phadia AB, Uppsala, Sweden) was provided by Phadia Korea (Seoul, Korea). Fecal samples were diluted 1:100, and the cutoff was $50 \mu \mathrm{g} / \mathrm{g}$. The RIDASCREEN ${ }^{\circledR}$ Calprotectin kit (R-Biopharm AG, Darmstadt, Germany) was provided by Asan Pharmaceuticals (Seoul, Korea). Fecal samples were diluted 1:50, and the cutoff was $50 \mu \mathrm{g} / \mathrm{g}$.

\section{Statistical Analysis}

The comparison among the three different calprotectin test kits was conducted using Passing and Bablok regression

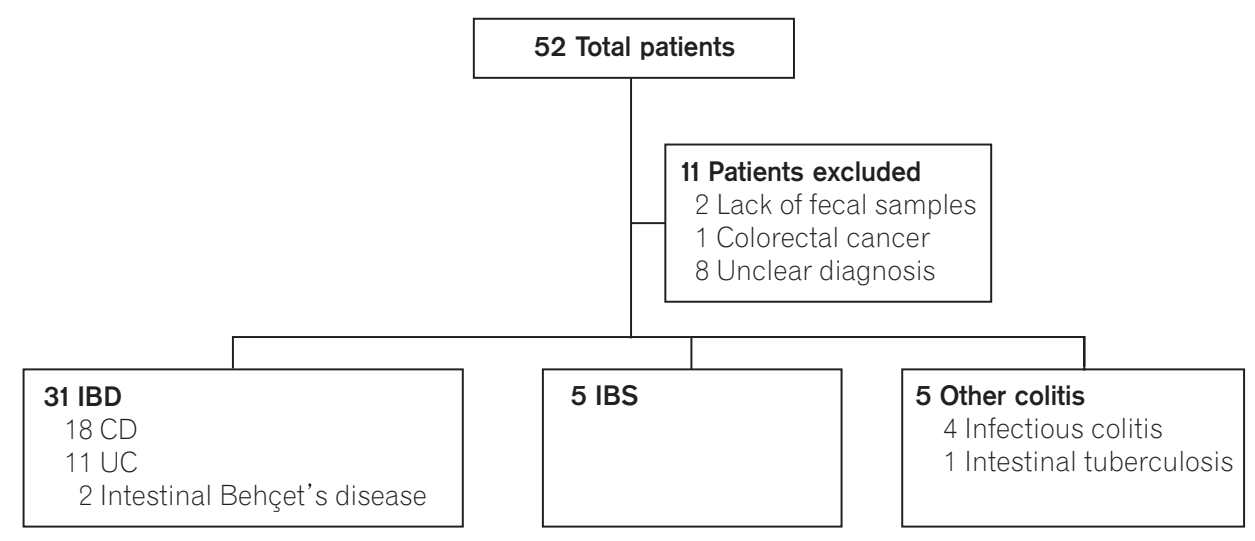

Fig. 1. Selection of the study subjects. 
and Spearman's rank correlation. Clinical and laboratory data on the patients were presented as mean $\pm \mathrm{SD}$, range, or n (\%), when appropriate. The Mann-Whitney test was used to compare the results of quantitative assays for fecal calprotectin and CRP between each disease group and to evaluate a possible correlation between fecal calprotectin concentration and disease location in patients with IBD (a $P$-value $<0.017$ was considered statistically significant according to Bonferroni's correction). The test performance of the three different calprotectin kits and a CRP assay was evaluated by means of sensitivity, specificity, positive and negative predictive values, and overall accuracy. The association between disease activity and fecal calprotectin was evaluated by means of Spearman's rank correlation coefficient ( $\mathrm{r}$ ) for nonparametric correlations. A $P$-value $<0.05$ was assumed to denote statistical significance. All statistical analyses were performed in the SPSS software, version 12.0 (SPSS Inc., Chicago, IL, USA), except for the Passing and Bablok regression, which was analyzed in the MedCalc software, version 16.2.1 (MedCalc, Ostend, Belgium). Vertical scatter plots were constructed using GraphPad Prism, version 6 (Graphpad Software Inc., LaJolla, CA, USA).

\section{RESULTS}

\section{Patients' Characteristics}

A total of 41 patients were analyzed in this study. Clinical characteristics of these patients are shown in Table 1. Twelve of the patients with CD had ileocolonic involvement, one had colonic involvement, and five had ileal involvement. Of the patients with UC, five had proctitis, and six had pancolitis.

Mean disease activity of CD patients was 199.3 points (range, 133-393 points). There were 14 patients (78\%) with CDAI $>150$. Mean disease activity among UC patients was
6.4 (range, $3-10)$. Five patients (45\%) had Mayo scores of 3 to 5 (mildly active disease), and six patients (55\%) had scores of 6 to 10 (moderately active disease).

The "other colitis" group consisted of four patients with infectious colitis and one patient with intestinal tuberculosis. Endoscopic findings revealed that the patients with infectious colitis had mucosal redness, erosions, and/or ulcers, and the patient with intestinal tuberculosis had circular ulcers with scars.

\section{Comparison of the Methods}

The correlation analysis was performed among Quantum Blue $^{\circledR}$ (as a standard value), EliA ${ }^{\mathrm{TM}}$, and RIDASCREEN ${ }^{\circledR}$ (Fig. 2). Between Quantum Blue ${ }^{\circledR}$ and EliA $^{\mathrm{TM}}$, the intercept of the regression line according to the Passing and Bablok regression was 7.19 (95\% CI, 23.82-39.23) and no significant deviation from 0 was present. The slope was 0.39 (95\% CI, 0.32-0.47) and a significant deviation from 1 was present. The intercept and slope were 54.70 (95\% CI, 1.20-107.67) and 0.09 (95\% CI, 0.07-0.17) between Quantum Blue ${ }^{\circledR}$ and RIDASCREEN $^{\circledR}$, and a significant deviation from 0 and 1 was present. Spearman's rank correlation coefficient was $0.90\left(P<0.0001 ; 95 \%\right.$ CI, 0.82-0.95) between Quantum Blue ${ }^{\circledR}$ and $\mathrm{EliA}^{\mathrm{TM}}$ and $0.72(P<0.0001 ; 95 \% \mathrm{CI}, 0.52-0.85)$ between Quantum Blue $^{\circledR}$ and RIDASCREEN ${ }^{\circledR}$. Although the three assays correlated significantly, the slopes and intercepts differed in pairwise comparisons.

\section{Test Characteristics of Fecal Calprotectin and CRP}

The results of quantitative assays for fecal calprotectin are presented in Fig. 3. The mean calprotectin level according to Quantum Blue ${ }^{\circledR}$ was 3,384 $\pm 3,450 \mu \mathrm{g} / \mathrm{g}$ (range, $218-9,960$ $\mu \mathrm{g} / \mathrm{g}$ ) in IBD, $120 \pm 190 \mu \mathrm{g} / \mathrm{g}$ (range, $30-459 \mu \mathrm{g} / \mathrm{g}$ ) in IBS, and

Table 1. Baseline Characteristics of the Study Subjects

\begin{tabular}{|c|c|c|c|c|c|}
\hline \multirow{2}{*}{ Variable } & \multicolumn{3}{|c|}{ IBD } & \multirow{2}{*}{ IBS } & \multirow{2}{*}{ Other colitis ${ }^{a}$} \\
\hline & CD & UC & Intestinal BD & & \\
\hline No. of patients & 18 & 11 & 2 & 5 & 5 \\
\hline Female sex & $4(22)$ & $4(36)$ & $2(100)$ & $2(40)$ & $1(20)$ \\
\hline Age $(y r)$ & $22 \pm 5(15-31)$ & $41 \pm 21(19-74)$ & $54 \pm 21(39-69)$ & $17 \pm 12(5-31)$ & $38 \pm 24(11-69)$ \\
\hline Disease activity & $199.3 \pm 67.7$ (133-393) & $6.4 \pm 2.3(3-10)$ & - & - & - \\
\hline $\begin{array}{l}\text { ues are presented } \\
\text { e the METHODS se } \\
\text { Al for CD and Ma } \\
\text { Behçet's disease. }\end{array}$ & $\begin{array}{l}\text { number }(\%) \text { or mean } \pm S \\
\text { on regarding the definit } \\
\text { score for ulcerative colit }\end{array}$ & & & & \\
\hline
\end{tabular}



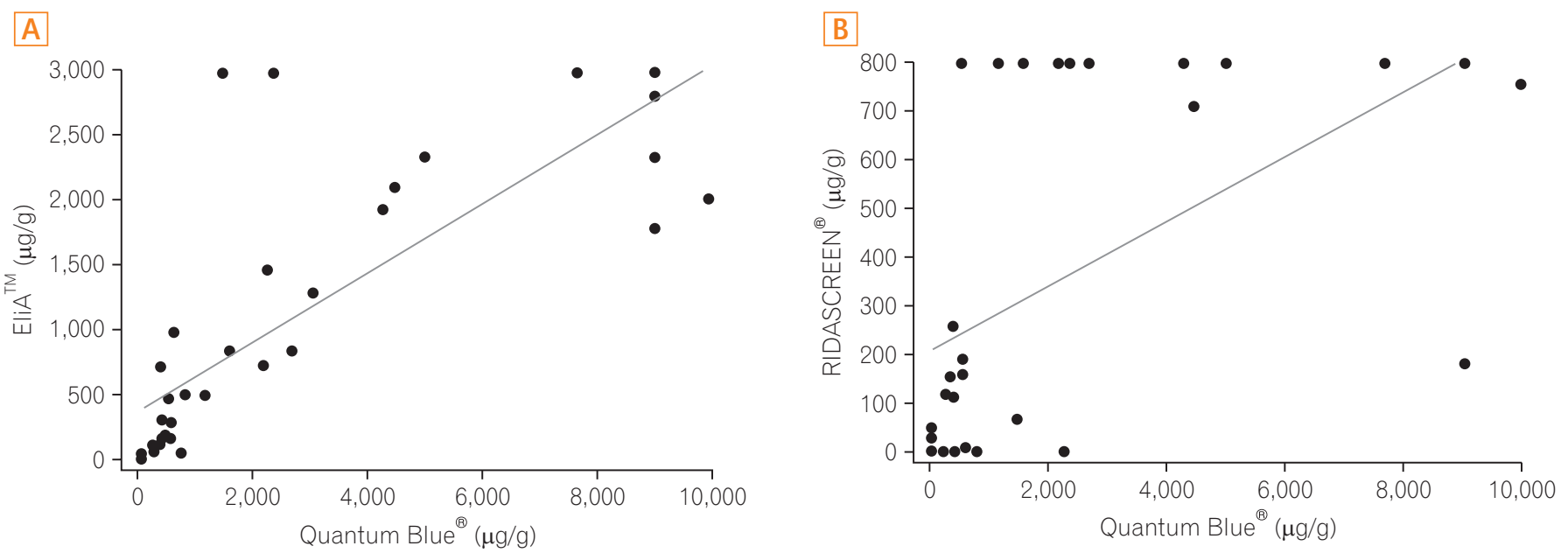

Fig. 2. The comparison of methods using Spearman's rank correlation. (A) The correlation and trend line between Quantum Blue ${ }^{\circledR}$ and Elii ${ }^{\mathrm{TM}}$ assays $(n=39, r=0.90, P<0.0001 ; 95 \% C C, 0.82-0.95)$. (B) The correlation and trend line between Quantum Blue ${ }^{\circledR}$ and RIDASCREEN ${ }^{\circledast}$ assays $(n=36, r=0.72$, $P<0.0001 ; 95 \% \mathrm{Cl}, 0.52-0.85)$.

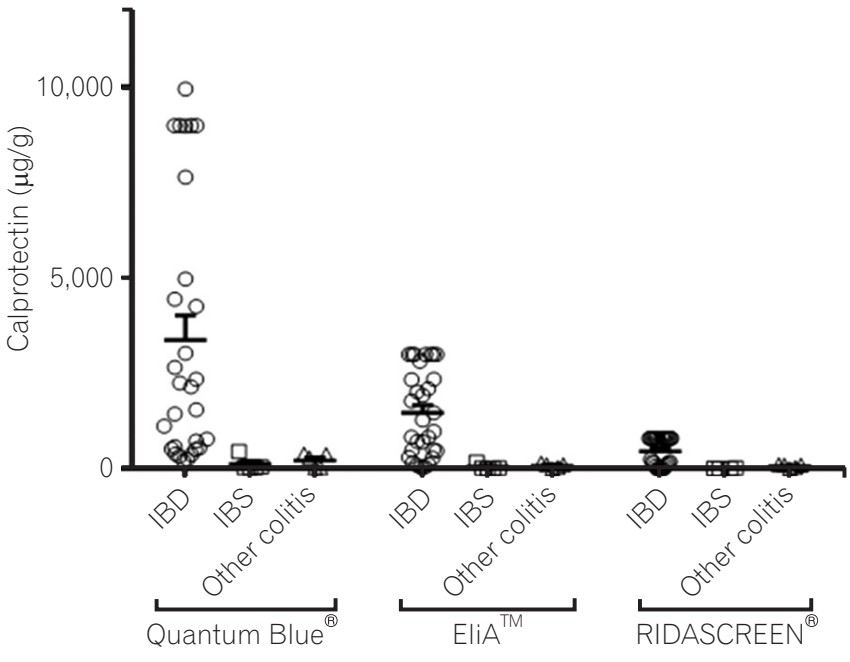

Fig. 3. Fecal calprotectin measured by the three fecal calprotectin kits in three groups of patients. Fecal calprotectin according to the three different kits was significantly elevated in IBD compared to IBS. Fecal calprotectin determined by the three kits was not different between IBS and the "other colitis" group (see the METHODS section for the definition).

$227 \pm 184 \mu \mathrm{g} / \mathrm{g}$ (range, $30-394 \mu \mathrm{g} / \mathrm{g}$ ) in "other colitis." According to $\mathrm{EliA}^{\mathrm{TM}}$, the mean calprotectin level was $1,476 \pm 1,127$ $\mu \mathrm{g} / \mathrm{g}$ (range, $47-3,000 \mu \mathrm{g} / \mathrm{g}$ ) in IBD, $54 \pm 74 \mu \mathrm{g} / \mathrm{g}$ (range, $15-187 \mu \mathrm{g} / \mathrm{g}$ ) in IBS, and $88 \pm 58 \mu \mathrm{g} / \mathrm{g}$ (range, $15-156 \mu \mathrm{g} / \mathrm{g}$ ) in "other colitis." According to RIDASCREEN ${ }^{\circledR}$, the mean calprotectin level was $467 \pm 360 \mu \mathrm{g} / \mathrm{g}$ (range, $0-800 \mu \mathrm{g} / \mathrm{g}$ ) in IBD, $11 \pm 13 \mu \mathrm{g} / \mathrm{g}$ (range, $0-27 \mu \mathrm{g} / \mathrm{g}$ ) in IBS, and $73 \pm 48 \mu \mathrm{g} / \mathrm{g}$ (range, $0-114 \mu \mathrm{g} / \mathrm{g}$ ) in "other colitis." The mean CRP concentration was $17.0 \pm 21.8 \mathrm{mg} / \mathrm{L}$ (range, $0.3-72.7 \mathrm{mg} / \mathrm{L}$ ) in IBD,
$0.9 \pm 0.8 \mathrm{mg} / \mathrm{L}$ (range, $0.4-2.3 \mathrm{mg} / \mathrm{L}$ ) in IBS, and $0.9 \pm 0.8 \mathrm{mg} /$ L (range, 0.4-2.3 mg/L) in "other colitis." Fecal calprotectin levels according to the three kits and CRP levels were significantly higher in patients with IBD than in patients with IBS $(P<0.017$, Bonferroni's correction). Fecal calprotectin concentrations determined by the three different kits and CRP levels were not different between IBS and "other colitis" $(P>0.017$ according to Bonferroni's correction).

\section{Test Performance of the Three Calprotectin Kits and CRP Assay}

The test performance (sensitivity/specificity/positive predictive values/negative predictive values) and overall accuracy in distinguishing between IBD and IBS or "other colitis" is summarized in Table 2. For differentiation of IBD from IBS, the overall accuracy was $97 \% / 94 \% / 84 \% / 58 \%$ for Quantum Blue $^{\circledR}$, EliA $^{\mathrm{TM}}$, RIDASCREEN ${ }^{\circledR}$, and CRP, respectively. For discrimination of IBD and "other colitis," the overall accuracy was $91 \% / 89 \% / 76 \% / 58 \%$ for Quantum Blue ${ }^{\circledR}$, EliA $^{\mathrm{TM}}$, RIDASCREEN $^{\circledR}$, and CRP, respectively. Neither fecal calprotectin levels nor the CRP levels were helpful for differentiation of IBS and "other colitis" (accuracy, 22\%-50\%).

\section{Correlation of Fecal Calprotectin Levels with Disease Activity among Patients with IBD}

Data on the correlation between fecal calprotectin levels determined by the three kits and disease activity are depicted in Fig. 4. In patients with CD, Quantum Blue ${ }^{\circledR}$ Calpro- 
Table 2. Test Performance and Overall Accuracy of the Three Fecal Calprotectin Kits and CRP Assay

\begin{tabular}{lccc}
\hline & IBD vs. IBS & IBD vs. other colitis & IBS vs. other colitis \\
\hline Calprotectin $(\mu \mathrm{g} / \mathrm{g})$, Quantum Blue ${ }^{\circledR}$ & $100 / 80 / 97 / 100 / 97$ & $100 / 40 / 91 / 100 / 91$ & $20 / 40 / 25 / 33 / 30$ \\
Calprotectin $(\mu \mathrm{g} / \mathrm{g})$, EliA ${ }^{\text {TM }}$ & $97 / 80 / 97 / 80 / 94$ & $97 / 40 / 91 / 67 / 89$ & $20 / 40 / 25 / 33 / 30$ \\
Calprotectin $(\mu \mathrm{g} / \mathrm{g})$, RIDASCREEN ${ }^{\circledR}$ & $82 / 100 / 100 / 44 / 84$ & $82 / 40 / 88 / 29 / 76$ & $0 / 40 / 0 / 33 / 22$ \\
CRP $(\mathrm{mg} / \mathrm{L})$ & $52 / 100 / 100 / 25 / 58$ & $52 / 100 / 100 / 25 / 58$ & $0 / 100 / 0 / 50 / 50$ \\
\hline
\end{tabular}

Sensitivity/specificity/positive predictive values/negative predictive values/overall accuracy $(\%)$. See the METHODS section regarding the definition of "other colitis."

tectin and EliA ${ }^{\mathrm{TM}}$ Calprotectin correlated significantly with CDAI $(P=0.004$ and $P=0.041$, respectively; $\mathrm{r}=0.66$ and $\mathrm{r}=0.49$, respectively). The RIDASCREEN ${ }^{\circledR}$ calprotectin level did not correlate statistically significantly with CDAI. In patients with UC, the mean time interval between fecal sampling and colonoscopy was 12.7 days (median, 10 days; range, 0-32 days). Eli ${ }^{\mathrm{TM}}$ Calprotectin correlated significantly with the Mayo score $(P=0.017, \mathrm{r}=0.70)$, whereas Quantum Blue ${ }^{\circledR}$ Calprotectin and RIDASCREEN ${ }^{\circledR}$ calprotectin results did not correlate with the Mayo score.

\section{Correlation of Fecal Calprotectin Levels with the Disease Location in Patients with IBD}

We also explored the relation between fecal calprotectin levels and the disease location in patients with IBD (Fig. $5)$. CD was located in the ileum in five patients, in the colon in one patient, and in the ileocolon in 12 patients. The mean calprotectin level according to Quantum Blue ${ }^{\circledR}$ was $1,156 \pm 975 \mu \mathrm{g} / \mathrm{g}$ (range, $256-2,250 \mu \mathrm{g} / \mathrm{g}$ ) in the ileum, 4,450 $\mu \mathrm{g} / \mathrm{g}$ in the colon, and 5,769 $\pm 3,192 \mu \mathrm{g} / \mathrm{g}$ (range, 1,555-9,960 $\mu \mathrm{g} / \mathrm{g}$ ) in the ileocolon. According to $\mathrm{EliA}^{\mathrm{TM}}$, the mean calprotectin concentration was $569 \pm 576 \mu \mathrm{g} / \mathrm{g}$ (range, 53-1,471 $\mu \mathrm{g} / \mathrm{g}$ ) in the ileum, $2,103 \mu \mathrm{g} / \mathrm{g}$ in the colon, and 2,202 \pm 834 $\mu \mathrm{g} / \mathrm{g}$ (range, $833-3,000 \mu \mathrm{g} / \mathrm{g}$ ) in the ileocolon. According to RIDASCREEN $^{\circledR}$, the mean calprotectin concentration was $214 \pm 335 \mu \mathrm{g} / \mathrm{g}$ (range, $0-800 \mu \mathrm{g} / \mathrm{g}$ ) in the ileum, $709 \mu \mathrm{g} / \mathrm{g}$ in the colon, and $796 \pm 13 \mu \mathrm{g} / \mathrm{g}$ (range, $758-800 \mu \mathrm{g} / \mathrm{g}$ ) in the ileocolon. According to all three fecal calprotectin kits, fecal calprotectin levels were significantly higher in CD patients with ileocolonic involvement than in CD patients with ileal involvement (all $P=0.004$ ). CDAI did not differ statistically significantly when stratified by disease location (all $P>0.05$ ). UC was identified as a type of proctitis in five patients, and pancolitis in six patients. The mean calprotectin level according to Quantum Blue ${ }^{\circledR}$ was $2,166 \pm 3,817 \mu \mathrm{g} / \mathrm{g}$ (range, $218-8,990 \mu \mathrm{g} / \mathrm{g}$ ) in proctitis and 2,353 $\pm 3,742 \mu \mathrm{g} / \mathrm{g}$ (range, $376-9,000 \mu \mathrm{g} / \mathrm{g}$ ) in pancolitis. According to $\mathrm{EliA}^{\mathrm{TM}}$, the mean calprotectin concentration was $947 \pm 1,199 \mu \mathrm{g} / \mathrm{g}$ (range, $116-3,000 \mu \mathrm{g} / \mathrm{g}$ ) in proctitis and 1,515 $\pm 1,273 \mu \mathrm{g} / \mathrm{g}$ (range, $283-3,000 \mu \mathrm{g} / \mathrm{g}$ ) in pancolitis. According to RIDASCREEN ${ }^{\circledR}$, the mean calprotectin concentration was $235 \pm 328 \mu \mathrm{g} / \mathrm{g}$ (range, $0-800 \mu \mathrm{g} / \mathrm{g}$ ) in proctitis and $226 \pm 295 \mu \mathrm{g} / \mathrm{g}$ (range, $0-800 \mu \mathrm{g} / \mathrm{g}$ ) in pancolitis. For all three kits, fecal calprotectin levels of patients with UC did not differ by disease location. The Mayo score was higher in pancolitis UC than in proctitis UC ( $7.7 \pm 2.1$ vs. $4.8 \pm 1.5$, respectively, $P=0.033)$. In two patients with intestinal Behçet's disease, one patient's lesion was located in the ileocecal valve, and the other patient's lesions were located in the ileocecal valve, terminal ileum, and colon. Calprotectin levels of the former and latter were 736 $\mu \mathrm{g} / \mathrm{g}$ and $1,128 \mu \mathrm{g} / \mathrm{g}$ according to Quantum Blue ${ }^{\circledR}, 47 \mu \mathrm{g} / \mathrm{g}$ and $500 \mu \mathrm{g} / \mathrm{g}$ according to $\mathrm{EliA}^{\mathrm{TM}}$, and untestable (due to a lack of fecal samples) and above $800 \mu \mathrm{g} / \mathrm{g}$ according to RIDASCREEN $^{\circledR}$, respectively.

\section{DISCUSSION}

Calprotectin, which was first described in 1980, has been proposed as a possible diagnostic marker of IBD. ${ }^{23}$ Conventional testing for calprotectin involves a laboratory ELISA, but the ELISA method is time-consuming, has a long turnaround time, and requires expertise. Recently, quantitative immunochromatographic point-of-care tests or quantitative enzyme immunoassays have become available as alternatives to the time-consuming ELISA. These tests can be performed in the clinic within 15 minutes. Only a small amount of stool is required, and the testing can be performed on stool samples kept for up to 1 week at room temperature because fecal calprotectin is resistant to bacterial degradation. Therefore, patients can bring a sample from home and receive a result on fecal calprotectin in a single visit.

In 2012, Coorevits et al. ${ }^{21}$ reported a comparison of a newly developed quantitative immunochromatographic pointof-care test (Quantum Blue ${ }^{\circledR}$ ) with an established ELISA test in terms of distinguishing organic from functional bowel 


\section{A}

Quantum Blue ${ }^{\circledR}$
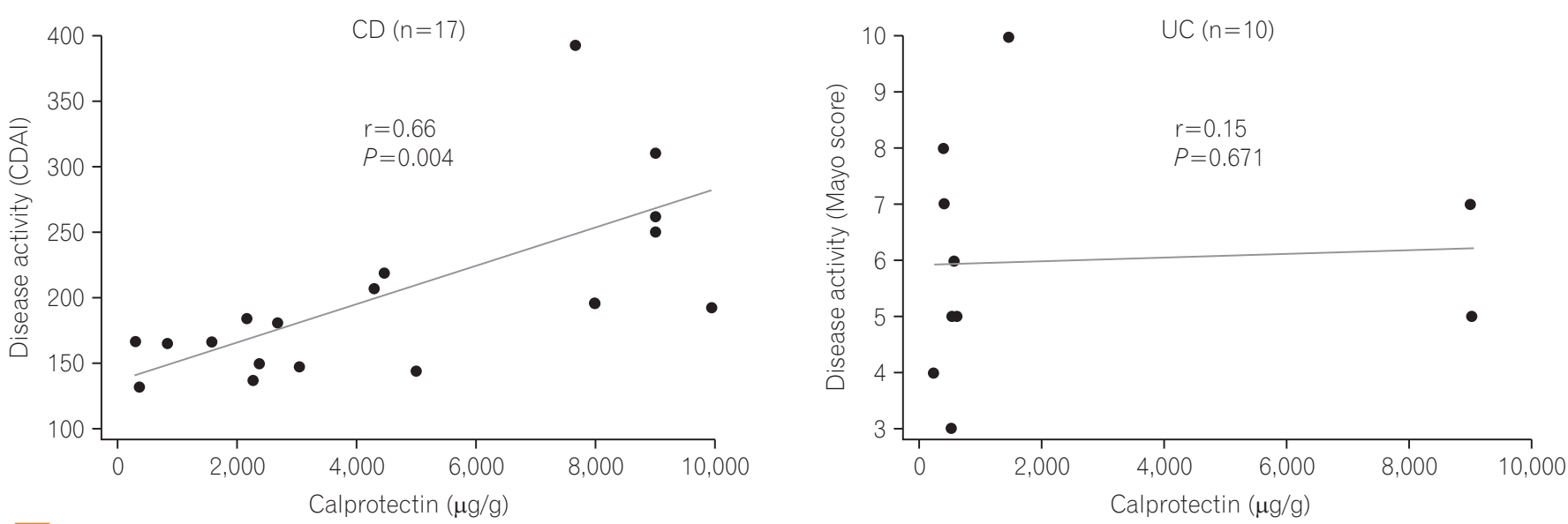

$\mathrm{B}_{\text {EliA }}^{\mathrm{TM}}$
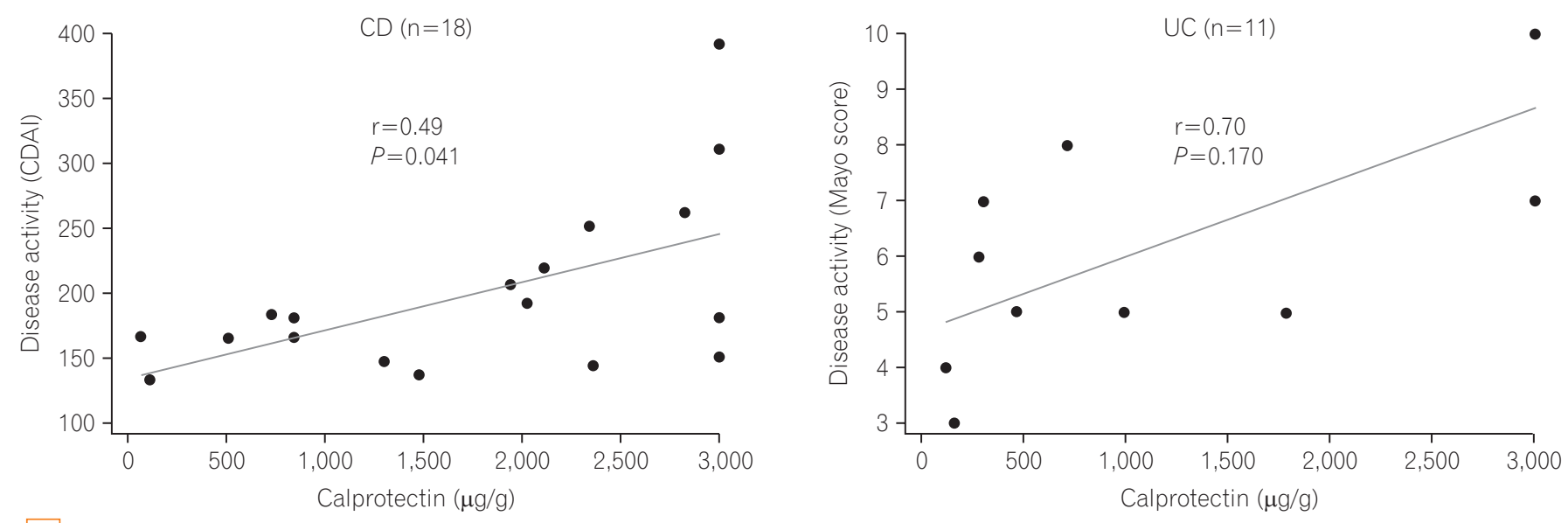

C

RIDASCREEN ${ }^{\circledR}$
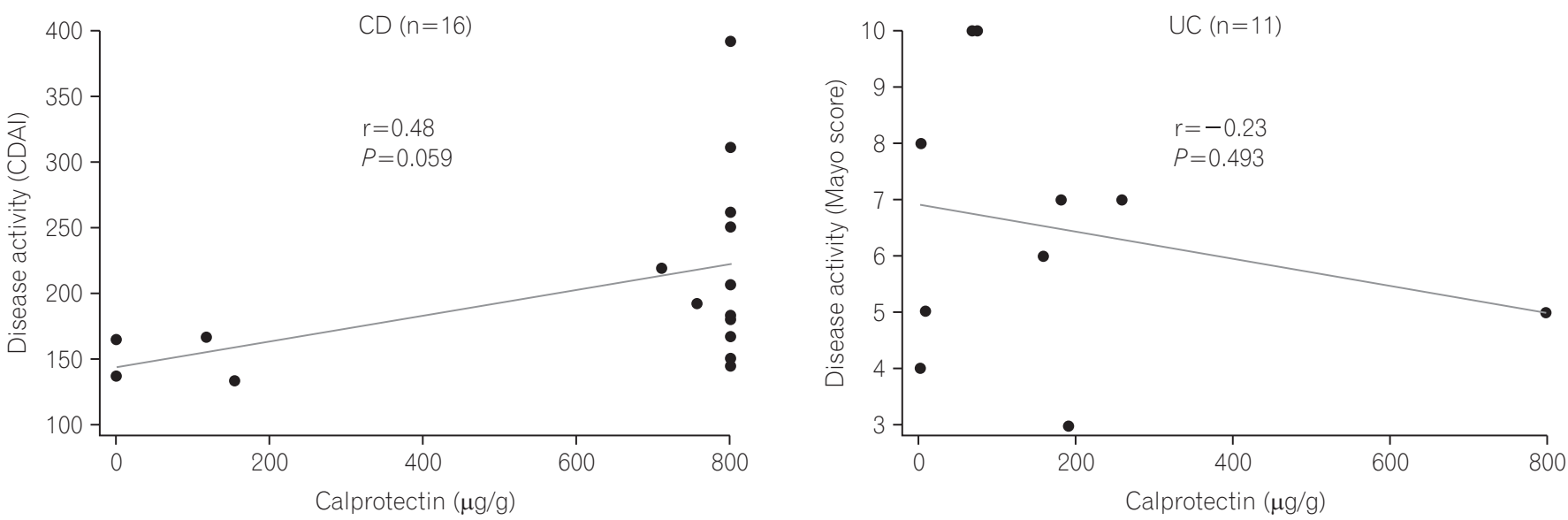

Fig. 4. (A-C) Correlation of the disease activity index with fecal calprotectin levels in IBD. In patients with $C D$, Quantum Blue ${ }^{\circledR}$ Calprotectin and Eli $A^{\top M}$ Calprotectin correlated significantly with the levels of CDAl. In patients with UC, EliA ${ }^{T M}$ Calprotectin correlated significantly with the Mayo score. $r_{\text {, }}$ Spearman's rank correlation coefficient. 

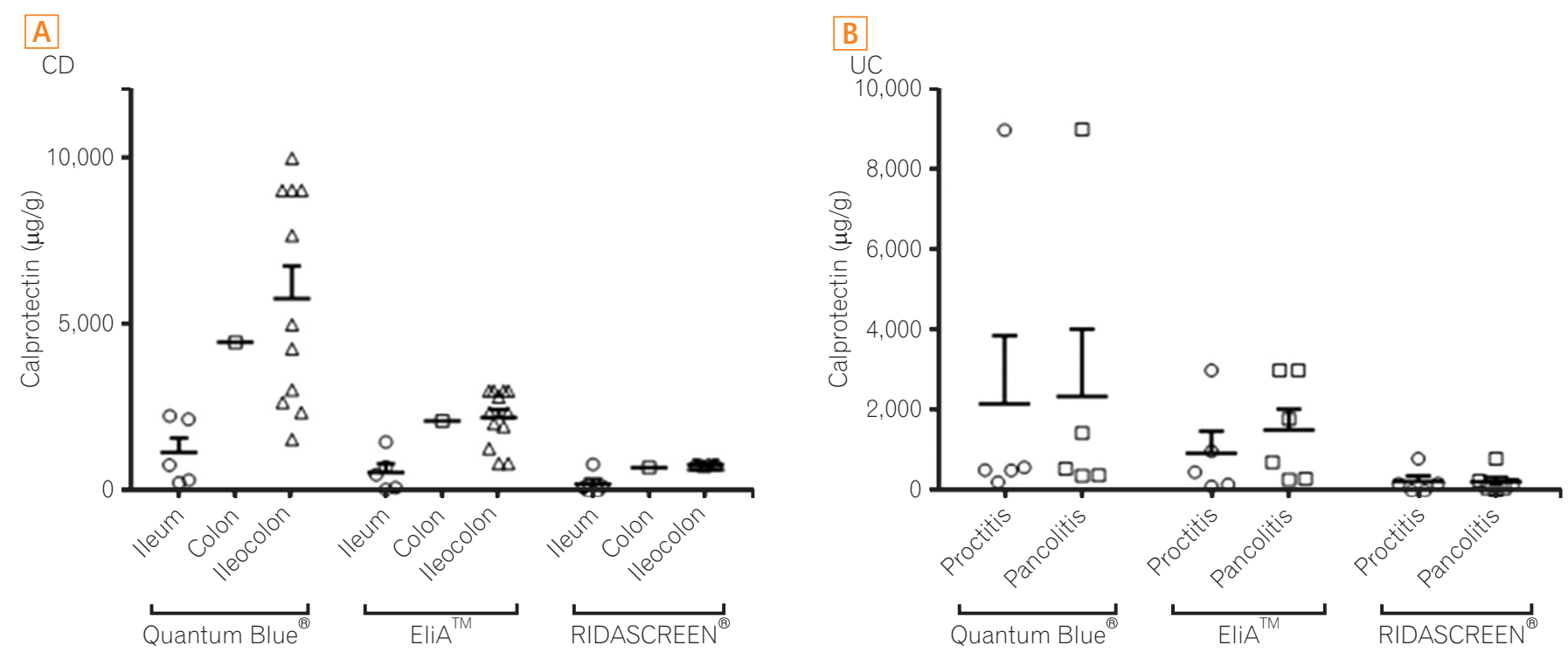

Fig. 5. Correlation of fecal calprotectin levels with the disease location in IBD. Solid lines indicate the mean of each group and error bars represent one standard error. (A) CD. According to all three kits, fecal calprotectin levels were significantly higher for ileocolonic involvement than for ileal involvement (all $P$-values, 0.004). (B) UC. For all three kits, fecal calprotectin levels did not differ by disease location.

diseases. The determination coefficient $\left(R^{2}\right)$ for 128 samples was 0.89 in the comparison of the methods, and the concordance ratio was $89.4 \%$. The point-of-care test was shown to be a reliable alternative to the ELISAs.

Recently, a new quantitative enzyme immunoassay, the $\mathrm{Eli}^{\mathrm{TM}}{ }^{\mathrm{TM}}$ calprotectin assay, was developed, and Oyaert et al. ${ }^{22}$ compared this assay with the point-of-care test among 183 patients with suspected IBD. Test performance of the Eli ${ }^{\mathrm{TM}}$ calprotectin assay was statistically equivalent to that of the point-of-care test.

Another quantitative enzyme immunoassay, the RIDASCREEN $^{\circledR}$ calprotectin assay, has not been validated in patients with suspected IBD. The present study compared these three fecal calprotectin kits to evaluate their initial diagnostic ability in patients with IBD, IBS, or "other colitis."

All three fecal calprotectin kits were superior to CRP in distinguishing IBD from IBS or "other colitis." Overall accuracy for differentiating IBD from IBS or "other colitis" was the best for Quantum Blue ${ }^{\circledR}$ Calprotectin $(97 \% / 91 \%)$, followed by EliA ${ }^{\mathrm{TM}}$ Calprotectin $(94 \% / 89 \%)$ and RIDASCREEN ${ }^{\circledR}$ Calprotectin $(84 \% / 76 \%)$.

Some articles about a comparison of calprotectin test kits were published recently. Mirsepasi-Lauridsen et al. ${ }^{24}$ compared three ELISA calprotectin tests among IBD patients and reported that the specificity of CALPRO, EK-CAL, and HK325 is $96 \%, 74 \%$, and $28 \%$, respectively. Therefore, the three calprotectin assays tested in the present study are comparable to an ELISA for diagnostic purposes. Labaere et al. ${ }^{25}$ compared three rapid immunochromatographic assays (including Quantum Blue ${ }^{\circledR}$ ), two ELISAs, and one automated immunoassay $\left(\mathrm{EliA}^{\mathrm{TM}}\right)$ in terms of diagnosis and followup of IBD. Sensitivity and specificity for the diagnosis of IBD were $83 \%$ and $68 \%$ for Quantum Blue ${ }^{\circledR}$ and $75 \%$ and $95 \%$ for $\mathrm{EliA}^{\mathrm{TM}}$, respectively. The present study revealed similar clinical performance.

On the other hand, efficacy of fecal-calprotectin kits does not seem to be satisfactory in discriminating IBD from the "other colitis" group, considering the low specificity observed (all $40 \%$ ). This is probably because the present study has a small sample size, and the study population is heterogeneous in terms of diagnosis and severity of the diseases. If the sample size of the "other colitis" group were larger, then the accuracy of fecal calprotectin kits might decrease as reported in another study. ${ }^{26}$ The three fecal calprotectin kits were not statistically helpful in discriminating between IBS and "other colitis" although calprotectin levels of patients with "other colitis" were found to be numerically higher than those of patients with IBS, as reported in other studies. ${ }^{22,26}$

Among patients with CD, results of Quantum Blue ${ }^{\circledR}$ Calprotectin and $\mathrm{EliA}^{\mathrm{TM}}$ Calprotectin correlated significantly with CDAI. The RIDASCREEN ${ }^{\circledR}$ calprotectin data, however, did not correlate with CDAI, possibly because the upper limit of RIDASCREEN ${ }^{\circledR}$ Calprotectin is lower than that of the other two tests. Among patients with UC, only $\mathrm{EliA}^{\mathrm{TM}}$ Calprotectin correlated significantly with the Mayo score. $\mathrm{EliA}^{\mathrm{TM}}$ Calprotectin appeared to better reflect disease activity 
in patients with UC than in patients with CD. Costa et al. ${ }^{27}$ reported that fecal calprotectin shows a higher correlation with disease activity of UC than with that of CD.

We also evaluated the correlation between fecal calprotectin levels and disease location in patients with IBD. There was a significant difference in calprotectin levels between CD patients with ileocolonic involvement and those with ileal involvement. This result is consistent with a report by Schoepfer et al., ${ }^{28}$ who studied the correlation of fecal calprotectin with the simple endoscopic score for CD among 140 patients with CD. Nevertheless, a comparison of colonic involvement with other affected locations must be confirmed in studies with a larger sample size because only one patient in the present study had colonic involvement.

The cost of these three calprotectin kits is $\$ 20-33$ per sample tested (Quantum Blue ${ }^{\circledR}>$ EliA $^{\mathrm{TM}}>$ RIDASCREEN $^{\circledR}$ ). Nonetheless, the final cost can vary depending on the number of samples tested at a time because each kit is packaged differently (25 tests/kit for Quantum Blue ${ }^{\circledR}, 48$ tests/kit for $\mathrm{EliA}^{\mathrm{TM}}$, and 96 tests/kit for RIDASCREEN ${ }^{\circledR}$ ).

Finally, when we evaluated the correlation between different calprotectin kits, the correlation coefficients were high, but when we performed regression analysis, significant differences were observed. This finding is in line with the data reported in other studies. ${ }^{25,29}$ Therefore, as authors of those studies pointed out, direct comparison of absolute calprotectin levels between different kits is inappropriate, and the use of the same kit is desirable during the follow-up of patients with IBD.

This study has several limitations. First, this study has a relatively small sample size. Therefore, larger studies will be necessary to confirm our results. Second, colonic involvement was present in only one patient with $\mathrm{CD}$, and this situation limited the comparison between colonic involvement and other affected locations. Nevertheless, the trends and results of analysis regarding correlation of fecal calprotectin with the disease location are consistent with data from other studies. ${ }^{21}$

In conclusion, fecal calprotectin tests are useful for distinguishing IBD from IBS or "other colitis" (in the descending order of performance): Quantum Blue ${ }^{\circledR}$ Calprotectin, EliA ${ }^{\mathrm{TM}}$ Calprotectin, and RIDASCREEN ${ }^{\circledR}$ Calprotectin.

\section{REFERENCES}

1. Hsu K, Champaiboon C, Guenther BD, et al. Anti-infective protective properties of S100 calgranulins. Antiinflamm Antiallergy Agents Med Chem 2009;8:290-305.
2. Tibble J, Teahon K, Thjodleifsson B, et al. A simple method for assessing intestinal inflammation in Crohn's disease. Gut 2000;47:506-513.

3. Tibble JA, Sigthorsson G, Foster R, Forgacs I, Bjarnason I. Use of surrogate markers of inflammation and Rome criteria to distinguish organic from nonorganic intestinal disease. Gastroenterology 2002;123:450-460.

4. von Roon AC, Karamountzos L, Purkayastha S, et al. Diagnostic precision of fecal calprotectin for inflammatory bowel disease and colorectal malignancy. Am J Gastroenterol 2007;102:803813.

5. Gisbert JP, McNicholl AG. Questions and answers on the role of faecal calprotectin as a biological marker in inflammatory bowel disease. Dig Liver Dis 2009;41:56-66.

6. van Rheenen PF, Van de Vijver E, Fidler V. Faecal calprotectin for screening of patients with suspected inflammatory bowel disease: diagnostic meta-analysis. BMJ 2010;341:c3369.

7. Lee KM. Fecal biomarkers in inflammatory bowel disease. Intest Res 2013;11:73-78.

8. Røseth AG, Aadland E, Grzyb K. Normalization of faecal calprotectin: a predictor of mucosal healing in patients with inflammatory bowel disease. Scand J Gastroenterol 2004;39:10171020.

9. Wagner M, Peterson CG, Stolt I, et al. Fecal eosinophil cationic protein as a marker of active disease and treatment outcome in collagenous colitis: a pilot study. Scand J Gastroenterol 2011;46:849-854.

10. Sipponen T, Savilahti E, Kärkkäinen P, et al. Fecal calprotectin, lactoferrin, and endoscopic disease activity in monitoring antiTNF-alpha therapy for Crohn's disease. Inflamm Bowel Dis 2008;14:1392-1398.

11. De Vos M, Dewit O, D'Haens G, et al. Fast and sharp decrease in calprotectin predicts remission by infliximab in anti-TNF naïve patients with ulcerative colitis. J Crohns Colitis 2012;6:557-562.

12. Molander P, af Björkesten CG, Mustonen H, et al. Fecal calprotectin concentration predicts outcome in inflammatory bowel disease after induction therapy with TNF alpha blocking agents. Inflamm Bowel Dis 2012;18:2011-2017.

13. Hämäläinen A, Sipponen T, Kolho KL. Infliximab in pediatric inflammatory bowel disease rapidly decreases fecal calprotectin levels. World J Gastroenterol 2011;17:5166-5171.

14. Ho GT, Lee HM, Brydon G, et al. Fecal calprotectin predicts the clinical course of acute severe ulcerative colitis. Am J Gastroenterol 2009;104:673-678.

15. Gisbert JP, Bermejo F, Pérez-Calle JL, et al. Fecal calprotectin and lactoferrin for the prediction of inflammatory bowel disease relapse. Inflamm Bowel Dis 2009;15:1190-1198. 
16. Costa F, Mumolo MG, Ceccarelli L, et al. Calprotectin is a stronger predictive marker of relapse in ulcerative colitis than in Crohn's disease. Gut 2005;54:364-368.

17. D'Incà R, Dal Pont E, Di Leo V, et al. Can calprotectin predict relapse risk in inflammatory bowel disease? Am J Gastroenterol 2008;103:2007-2014.

18. Kallel L, Ayadi I, Matri S, et al. Fecal calprotectin is a predictive marker of relapse in Crohn's disease involving the colon: a prospective study. Eur J Gastroenterol Hepatol 2010;22:340-345.

19. Dignass A, Van Assche G, Lindsay JO, et al. The second European evidence-based Consensus on the diagnosis and management of Crohn's disease: current management. J Crohns Colitis 2010;4:28-62.

20. Dignass A, Lindsay JO, Sturm A, et al. Second European evidence-based consensus on the diagnosis and management of ulcerative colitis part 2: current management. J Crohns Colitis 2012;6:991-1030.

21. Coorevits L, Baert FJ, Vanpoucke HJ. Faecal calprotectin: comparative study of the Quantum Blue rapid test and an established ELISA method. Clin Chem Lab Med 2013;51:825-831.

22. Oyaert M, Trouvé C, Baert F, De Smet D, Langlois M, Vanpoucke H. Comparison of two immunoassays for measurement of faecal calprotectin in detection of inflammatory bowel disease: (pre)-analytical and diagnostic performance characteristics. Clin Chem Lab Med 2014;52:391-397.
23. Fagerhol MK, Dale I, Anderson T. Release and quantitation of a leucocyte derived protein (L1). Scand J Haematol 1980;24:393398.

24. Mirsepasi-Lauridsen HC, Bachmann Holmetoft U, Ingdam Halkjær S, Angeliki Krogfelt K, Munk Petersen A. Comparison of three commercial fecal calprotectin ELISA test kits used in patients with inflammatory bowel disease. Scand J Gastroenterol 2016;51:211-217.

25. Labaere D, Smismans A, Van Olmen A, et al. Comparison of six different calprotectin assays for the assessment of inflammatory bowel disease. United European Gastroenterol J 2014;2:3037.

26. Schoepfer AM, Trummler M, Seeholzer P, Criblez DH, Seibold F. Accuracy of four fecal assays in the diagnosis of colitis. Dis Colon Rectum 2007;50:1697-1706.

27. Costa F, Mumolo MG, Bellini M, et al. Role of faecal calprotectin as non-invasive marker of intestinal inflammation. Dig Liver Dis 2003;35:642-647.

28. Schoepfer AM, Beglinger C, Straumann A, et al. Fecal calprotectin correlates more closely with the simple endoscopic score for Crohn's disease (SES-CD) than CRP, blood leukocytes, and the CDAI. Am J Gastroenterol 2010;105:162-169.

29. Sun S, Cavey T, Peltier L, Bendavid C, Bouguen G. Letter: wide variation in faecal calprotectin values according to the assay. Aliment Pharmacol Ther 2016;43:177-178. 